\title{
Community Composition of Elasmobranch Fishes Utilizing Intertidal Sand Flats in Moreton Bay, Queensland, Australia ${ }^{1}$
}

\author{
Simon 7. Pierce, ${ }^{2,3}$ Tracey B. Scott-Holland, ${ }^{2}$ and Michael B. Bennett ${ }^{2}$
}

\begin{abstract}
Thirteen elasmobranch species were collected during a 4-yr survey of the intertidal margins of Moreton Bay, a large subtropical embayment in southeastern Queensland, Australia. Stingrays were the most common large predators in the intertidal zone, with total catch dominated numerically by blue-spotted maskray, Neotrygon kublii (53.8\%); estuary stingray, Dasyatis fluviorum (22.2\%); and brown whipray, Himantura toshi $(10.2 \%)$. There was a significant female bias within intertidal populations of N. kublii and D. fluviorum. Courtship behaviors were observed in July and September in D. fluviorum and in January for whitespotted eagle ray, Aetobatus narinari. Dasyatis fluviorum, a threatened Australian endemic stingray, remains locally abundant within the bay. Overall, the inshore elasmobranch fauna of Moreton Bay is relatively species rich compared with similar studies elsewhere in Australia, emphasizing the regional importance of this ecosystem.
\end{abstract}

Moreton BAy is a large $\left(1,523 \mathrm{~km}^{2}\right)$ subtropical embayment on the east coast of Australia. The bay is surrounded by the fastgrowing southeastern Queensland urban region, home to over 2.8 million residents in 2006 (EPA 2008a). Increasing population density has led to intensive land use and associated nutrient runoff, resulting in a serious degradation in water quality in river estuaries and western Moreton Bay (Dennison and Abal 1999). The bay is also heavily used for recreation and commercial activities including major commercial and recreational fisheries, shipping, boating, and marine tourism (Johnson 1999, EPA 2008a). However, despite high anthropogenic pressure, Moreton Bay continues to support a diverse and rela-

\footnotetext{
${ }^{1}$ This research was funded by grants from The University of Queensland and the Tangalooma Marine Education and Research Foundation. Manuscript accepted 4 July 2010.

${ }^{2}$ School of Biomedical Sciences, The University of Queensland, St. Lucia, Queensland 4072, Australia.

${ }^{3}$ Corresponding author (e-mail: simonjpierce@ gmail.com).
}

Pacific Science (2011), vol. 65, no. 2:235-247

doi: $10.2984 / 65.2 .235$

(C) 2011 by University of Hawai'i Press

All rights reserved tively abundant marine mammal fauna (Chilvers et al. 2005) and at least 750 fish species (Johnson 1999). The area is also an internationally recognized Ramsar-listed wetland for migratory shorebird species (Thompson 1993, EPA 2008b).

Shark and ray populations can be rapidly depleted by anthropogenic pressures (Stevens et al. 2000, Fowler et al. 2005), and a high abundance of these large predatory fishes is increasingly held to be indicative of a healthy ecosystem (Friedlander and DeMartini 2002, Robbins et al. 2006, Stevenson et al. 2007). Although much of the bay retains a high biological diversity, and no major loss of species is known to have occurred (Dennison and Abal 1999, Chilvers et al. 2005), analysis of historical data sets has suggested that populations of large marine carnivores have declined since the beginning of large-scale settlement (Jackson et al. 2001, Pandolfi et al. 2003, Lotze et al. 2006). One elasmobranch species that was previously known from the bay, the green sawfish, Pristis zijsron, has not been recorded locally since the 1960s (Johnson 1999), and anecdotal observations suggest that estuary stingray, Dasyatis fluviorum, have also declined (Kyne et al. 2003).

A lack of baseline information on the habitat preferences, abundance, and biology of elasmobranchs hampers the management of 
this group in inshore ecosystems such as Moreton Bay. Basic information on species composition and abundance in the region is scarce. Johnson (1999) compiled an annotated checklist of 52 elasmobranch species recorded from Moreton Bay and provided contemporary abundance estimates based on museum records and field surveys. Batoids are often underrepresented in conventional faunal surveys because their dorsoventrally flattened bodies and relatively low movement rates make them difficult to capture using static sampling techniques (White and Potter 2004). However, stingrays play an important ecological role in soft-bottom ecosystems (VanBlaricom 1982, Thrush et al. 1991, Heithaus 2004), and some species are highly susceptible to population decline (Stobutzki et al. 2002). In this study we provide a focused survey of the benthic elasmobranch species found in intertidal sand-flat habitats around the margins of the bay, their relative abundance and population structure, and evaluate the importance of this environment to the conservation and management of these fishes.

\section{MATERIALS AND METHODS}

Moreton Bay is contained within the broader Moreton Bay Marine Park in southeastern Queensland, Australia (centered on $27^{\circ} 15^{\prime} \mathrm{S}$, $153^{\circ} 15^{\prime} \mathrm{E}$ ). The bay is bounded on the east by three sand islands: Moreton I., North Stradbroke I. (NSI), and South Stradbroke I. Eastern Moreton Bay is subject to considerable oceanic input, promoting stable salinities and water temperature, and low levels of turbidity (Dennison and Abal 1999, Johnson 1999). The western bay is characterized by wide, shallow bays interspersed with headlands and rivers, with these freshwater inputs leading to variable salinity and turbidity (Dennison and Abal 1999, Johnson 1999). Further descriptions of the habitats within the bay, including the intertidal regions, are provided in Johnson (1999), Manson et al. (2003), and Zharikov et al. (2005).

Sampling for this study occurred between April 2002 and April 2006 in the middle regions of Moreton Bay (see Figure 1). Preliminary fieldwork was undertaken at a number of sites in that area to confirm elasmobranch presence and to select appropriate collection techniques, given that the species found in the intertidal environment are predominantly batoids. Four sites were selected for repeated sampling based on their accessibility and the broadly similar sand- or mudflat habitats at each location: (1) the northern Wanga Wallen Banks (WWB) are centered on $27^{\circ} 24.58^{\prime}$ $\mathrm{S}, 153^{\circ} 26.21^{\prime} \mathrm{E}$ and lie immediately south of the town of Amity on NSI; (2) One Mile Bay $(\mathrm{OMB}), 27^{\circ} 29.68^{\prime} \mathrm{S}, 153^{\circ} 23.94^{\prime} \mathrm{E}$, is located $8.1 \mathrm{~km}$ south of the Wanga Wallen Banks on the west coast of NSI adjacent to the town of Dunwich; (3) Hays Inlet (HI), $27^{\circ} 15.68^{\prime} \mathrm{S}$, $153^{\circ} 4.58^{\prime} \mathrm{E}$, is a semi-enclosed embayment on the northwestern side of Moreton Bay; (4) the Wynnum Banks (WB), $27^{\circ} 25.11^{\prime} \mathrm{S}, 153^{\circ}$ $10.56^{\prime} \mathrm{E}$, are located adjacent to the Wynnum Creek mouth in the western bay. The two former sites are located in the eastern bay, and the two latter sites are in the western bay. Opportunistic samples were also collected from similar habitats adjacent to these four main sites.

Details of sampling methods and periodicity are provided in Pierce et al. (2009) and Table 1. Seine (WWB, OMB, and $\mathrm{HI})$ and tunnel nets $(\mathrm{WB})$ were fished over intertidal flats in shallow $(<1.5 \mathrm{~m})$ water during early morning or evening mid- to high tides. Pilot studies found that catch rates of elasmobranchs during daylight hours were low, and subsequently the majority of sampling effort took place in darkness. All nets covered the entire water column. Because batoids did not usually enmesh in seine nets, they were corralled into shallow water where the net could be ringed-off, so that individual fish could be captured with hand nets.

All elasmobranchs were identified to species level (Last and Stevens 2009). The relative abundance of each species in catches was qualitatively assigned following the method of Johnson (1999): "rare" denotes one to four specimens collected; "uncommon" indicates five to nine individuals; "common" represents 10 to 100 individuals; and "abundant" is used where $>100$ individuals were caught. Species diversity at the three sites sampled regularly with seine nets (WWB, OMB, and $\mathrm{HI})$ was 
investigated using standard diversity indices implemented in PRIMER-6 (Clarke and Gorley 2001, Clarke and Warwick 2001). Species richness, as measured simply by the total number of species $(S)$, is often correlated with sampling effort; therefore Margalef's In$\operatorname{dex}(d)$ was used as a complementary measure to control for the total number of individuals caught at each site using the formula $(S-1)$ / $\log (N)$, where $N$ denotes the total number of individuals caught. Shannon $\left(\log _{\mathrm{e}}\right.$ base; $\left.H^{\prime}\right)$ and Simpson $(1-\lambda)$ indices considered both richness and evenness. The Shannon Index followed the formula $-\sum\left(P^{*} \log (P \mathrm{i})\right)$, where $P \mathrm{i}$ is the proportion of individuals of a given species. The Simpson Index was calculated by $1-\sum\left(N_{i}^{*}\left(N_{i}-1\right)\right) / N^{*}(N-1)$, where $N_{i}$ is the number of individuals of a given species. Pielou's Evenness Index ( $\left.\mathcal{f}^{\prime}\right)$ was used to assess the equitability or relative abundance of species $\left(H^{\prime} / \log (S)\right)$.

Biological notes are also presented for some species sampled during these studies. Specimens were either retained for lifehistory studies or tagged and released. Males were defined as immature or mature following external examination of the claspers; the presence of elongated and calcified claspers was used as an indication of maturity following Walker (2005) and Pierce et al. (2009). Females were assessed as mature based on macroscopic examination of uteri, ovary, and oviductal gland condition following general methods outlined in Pierce et al. (2009). Total length, measured as flexed total length (TL) (Francis 2006), was taken for sharks, shovelnose rays, and guitarfish. Straight-line disk width (DW) was measured across the ventral surface for other batoids. Stingrays and small shovelnose rays and guitarfish were tagged with a T-bar anchor tag (type TBA-2, Hallprint, South Australia) in the pectoral fin musculature adjacent to the pectoral girdle. All sharks were tagged in the dorsal musculature adjacent to the first dorsal fin. All sharks $<1.5 \mathrm{~m}$ TL and sharklike rays and stingrays of $<1.2 \mathrm{~m}$ DW were transported to shore to facilitate measuring and tagging. Sexual segregation within individual species was assessed using $z$-tests implemented in SigmaStat v2.03 (SPSS Inc.).
RESULTS

Five hundred and twenty-one elasmobranchs were caught from the four primary study areas (Figure 1, Table 1), with total catch from all sites comprising 627 individuals from 13 species and eight families (Table 2). Though sampling was not standardized for effort or for examining temporal trends, there was observational evidence for decreased total catches at night during cooler months (May to July) when water temperatures were generally below $17^{\circ} \mathrm{C}$. Neotrygon kublii was the most common species at three of the four sites and comprised $53.8 \%$ of the total catch numerically. Dasyatis fluviorum was the most abundant large species ( $>5 \mathrm{~kg}$ body mass), constituting $22.2 \%$ of total catch. Himantura toshi, as redescribed by Last et al. (2008), was also common, comprising $10.2 \%$ of total catch. Two other species, Glaucostegus typus (3.7\% of total catch) and Aptychotrema rostrata (3.4\%), were also caught at all four sites. Neotrygon kublii and $H$. toshi were partial exceptions to the general trend of low daytime catches, with juvenile $H$. toshi $<30 \mathrm{~cm}$ DW in particular being regularly caught during daylight hours. Species richness was highest at $\mathrm{OMB}$, where 10 species were caught (Table 1), although both NSI sites (OMB and WWB) were equivalent when richness was corrected for sample size using Margalef's index. Catches in the western bay were substantially dominated by N. kublii. Aetobatus narinari, Chiloscyllium punctatum, Himantura fai, H. uarnak, Orectolobus maculatus, Rhynchobatus laevis, and Trygonoptera testacea were all caught solely from the two eastern sites, whereas Gymnura australis was caught only at HI.

Sex- or size-based segregation was noted in the overall catch of some species. Intertidal populations of $N$. kublii (z-test, $n=317$, $P<.001$ ) and D. fluviorum (z-test, $n=139$, $P<.001)$ were significantly biased toward females (Table 3). Although small sample sizes precluded a quantitative comparison of sexual- or size-based segregation within sites, there was some evidence that this may occur in D. fluviorum. Catches at OMB comprised 20 immature females and only one immature male. In contrast, all 16 D. fluviorum collected 


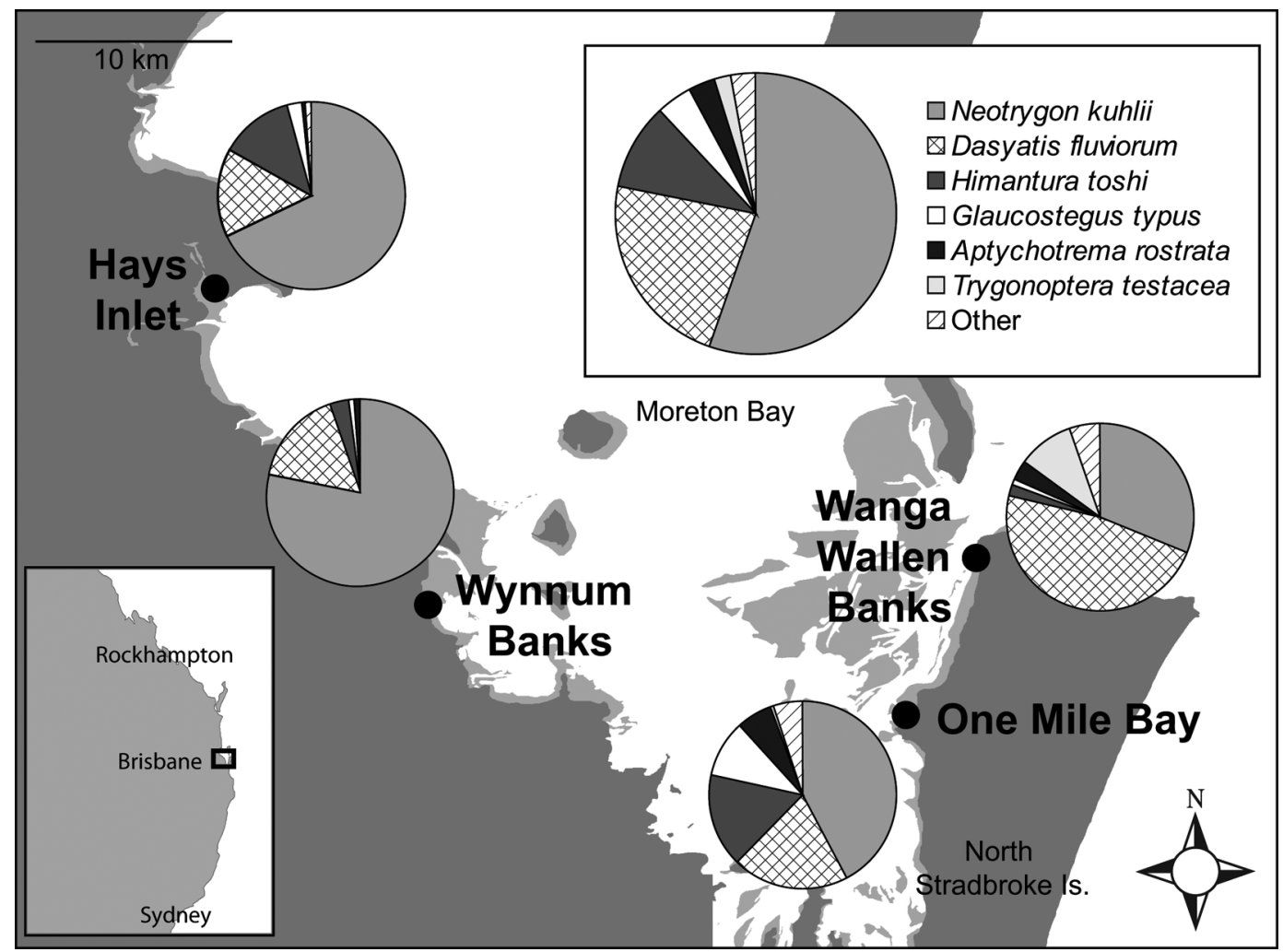

FIGURE 1. Moreton Bay study sites and relative catch compositions. Inset map (lower left) indicates the position of the bay on the eastern coast of Australia. Inset graph (upper right) shows the overall species composition for Moreton Bay and key.

TABLE 1

Collection Methods and Sampling Effort (2002 to 2006 Data Combined) at Each Study Location within Moreton Bay

\begin{tabular}{|c|c|c|c|c|c|c|c|c|c|c|}
\hline \multirow[b]{2}{*}{ Site $^{a}$} & \multicolumn{4}{|c|}{ Sampling Regime } & \multicolumn{2}{|c|}{ Catch Data } & \multicolumn{4}{|c|}{ Diversity Indices ${ }^{b}$} \\
\hline & Summer & Autumn & Winter & Spring & No. Species & $n$ & $d$ & $f^{\prime}$ & $H^{\prime}$ & $1-\lambda$ \\
\hline HI & 1 & 3 & 6 & 16 & 6 & 171 & 0.97 & 0.55 & 0.98 & 0.50 \\
\hline WWB & 9 & 3 & 3 & 0 & 9 & 93 & 1.77 & 0.63 & 1.39 & 0.67 \\
\hline $\mathrm{OMB}$ & 5 & 16 & 9 & 7 & 10 & 161 & 1.77 & 0.70 & 1.62 & 0.74 \\
\hline WB & 1 & 3 & 0 & 0 & 5 & 96 & - & - & - & - \\
\hline Total & \multicolumn{4}{|c|}{82} & 13 & 521 & & & & \\
\hline
\end{tabular}

"HI, Hays Inlet; WWB, Wanga Wallen Banks; OMB, One Mile Bay; WB, Wynnum Banks.

${ }^{b}$ Results of the Margalef $(d)$, Pielou $\left(\mathcal{f}^{\prime}\right)$, Shannon $\left(H^{\prime}\right)$, and Simpson $(1-\lambda)$ indices are included for each site except WB, where a different collection method was used. 
TABLE 2

Elasmobranch Catches, Ranked by Frequency of Occurrence

\begin{tabular}{llrrrr}
\hline \hline Family & \multicolumn{1}{c}{ Species } & $n$ & Tagged & Recaptured & Abundance $^{a}$ \\
\hline Dasyatidae & Neotrygon kublii & 317 & 124 & $20(16.1 \%)$ & Abundant \\
Dasyatidae & Dasyatis fluviorum & 139 & 52 & $5(9.6 \%)$ & Abundant \\
Dasyatidae & Himantura toshi & 64 & 39 & $8(20.5 \%)$ & Common \\
Rhinobatidae & Glaucostegus typus & 23 & 20 & $1(5 \%)$ & Common \\
Rhinobatidae & Aptychotrema rostrata & 21 & 14 & 0 & Common \\
Hemiscyllidae & Chiloscyllium punctatum & 17 & 12 & 0 & Common \\
Urolophidae & Trygonoptera testacea & 11 & 5 & $1(20 \%)$ & Common \\
Rhynchobatidae & Rhynchobatus laevis & 4 & 2 & 0 & Rare \\
Gymnuridae & Gymnura australis & 3 & 1 & 0 & Rare \\
Myliobatidae & Aetobatus narinari & 3 & 1 & 0 & Rare \\
Orectolobidae & Orectolobus maculatus & 2 & 0 & 0 & Rare \\
Dasyatidae & Himantura uarnak & 2 & 0 & 0 & Rare \\
Dasyatidae & Himantura fai & 1 & 1 & 0 & Rare \\
Total & & 627 & 271 & $35(12.9 \%)$ &
\end{tabular}

${ }^{a}$ Relative abundances were categorized as abundant (>100 individuals), common $(10-100)$, or rare $(<5)$.

TABLE 3

Biological Notes for Each Species

\begin{tabular}{|c|c|c|c|c|c|}
\hline Species & $n$ & Size Range & M:F Sex Ratio & Female Maturity & Male Maturity \\
\hline Neotrygon kublii & 317 & $11.5-46.5 \mathrm{DW}$ & $1: 1.54^{*}$ & $M \geq 30 \mathrm{DW}$ & $M \geq 28.7 \mathrm{DW}$ \\
\hline Dasyatis fluviorum & 139 & $15.5-76.2 \mathrm{DW}$ & $1: 2.6^{*}$ & $M \geq 63.9 \mathrm{DW}$ & $M \geq 41.2 \mathrm{DW}$ \\
\hline Himantura toshi & 66 & $19-69.2 \mathrm{DW}$ & $1: 1.89$ & - & $M \geq 53 \mathrm{DW}$ \\
\hline Glaucostegus typus & 23 & 39-87 TL & $1: 2$ & - & - \\
\hline Aptychotrema rostrata & 21 & 45-88 TL & $1: 0.9$ & - & $M \leq 64 \mathrm{TL}$ \\
\hline Chiloscyllium punctatum & 17 & 68-119 TL & $1: 0.6$ & - & $M \geq 98 \mathrm{TL}$ \\
\hline Trygonoptera testacea & 10 & 18.6-28.6 DW & $1: 1$ & $M \leq 26.8 \mathrm{DW}$ & $M \leq 18.6 \mathrm{DW}$ \\
\hline Rhynchobatus laevis & 5 & $70-110 \mathrm{TL}$ & - & - & - \\
\hline Aetobatus narinari & 3 & $98.5-150 \mathrm{DW}$ & $1: 0.5$ & - & $M \geq 98.5 \mathrm{DW}$ \\
\hline Gymnura australis & 2 & 45-61 DW & $1: 1$ & & $M \leq 47 \mathrm{DW}$ \\
\hline Himantura uarnak & 2 & 100-150 DW & - & - & - \\
\hline Himantura fai & 1 & $77 \mathrm{DW}$ & - & - & - \\
\hline Orectolobus maculatus & 1 & $\sim 90 \mathrm{TL}$ & - & - & - \\
\hline
\end{tabular}

Note: Where available, maturity was based on the largest immature individual $(M \geq \mathrm{DW})$ or the smallest mature individual examined $(M \leq \mathrm{DW})$. Measurements are presented in $\mathrm{cm}$.

* Indicates significant differences in sex ratios $(P<.05)$.

at $\mathrm{WB}$ were immature females. All of the small $(<25 \mathrm{~cm}$ DW) D. fluviorum caught during this study $(n=6)$ were from HI. All T. testacea examined were mature, whereas both adults and juveniles of N. kublii, D. fluviorum, $H$. toshi, and A. rostrata were collected (Figure 2). Some N. kublii and G. typus were captured as neonates or at close to birth size, indicating that parturition is likely to occur within Moreton Bay. All G. typus specimens were neonates or small juveniles ranging from 39 $\mathrm{cm}$ to $87 \mathrm{~cm}$ TL, with neonates $<40 \mathrm{~cm}$ TL caught between March and May. One larger $>150 \mathrm{~cm}$ TL G. typus was caught at OMB and released at the point of capture. No other large individuals of this species were sighted in the intertidal region. Uterine eggs were present in five female D. fluviorum caught in March 2005 and in two female Trygonoptera testacea of 26.8 and $28.6 \mathrm{~cm}$ DW caught 1 February and 2 March 2005, respectively, all at WWB. 

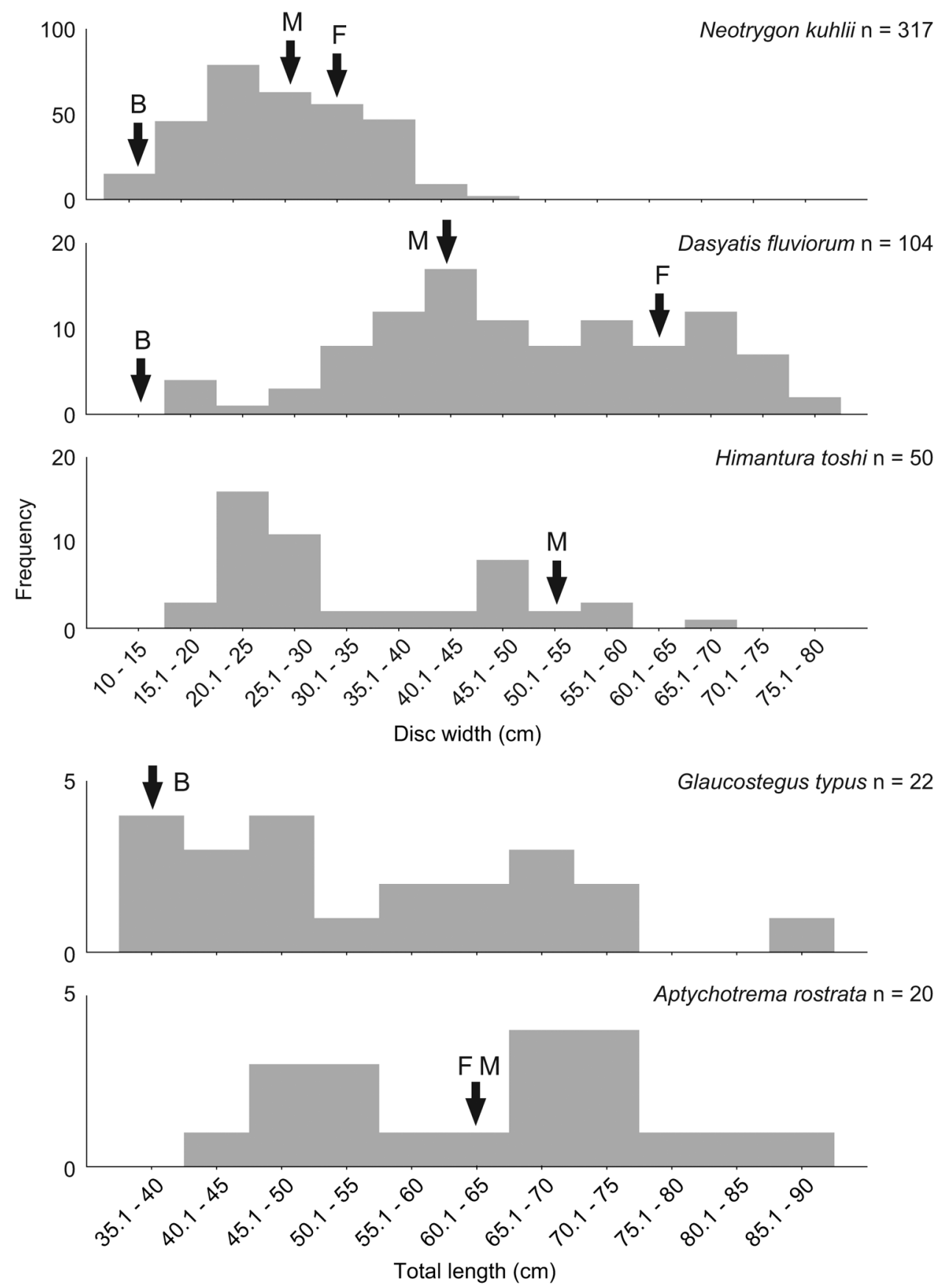

FIGURE 2. Size-frequency graphs for all species where $n>20$. Arrows denote size at birth (B) and, based on the smallest mature individuals, male maturity $(\mathrm{M})$ and female maturity $(\mathrm{F})$ where known. 
Courtship behaviors were observed in two species, D. fluviorum and A. narinari. A male and female $D$. fluviorum were observed swimming together for approximately $3 \mathrm{~min}$ in 80 $\mathrm{cm}$ water depth in $\mathrm{OMB}$ at night (2100 hours) on 30 July 2003. The male was positioned above the larger female biting the posterior region of her left pectoral fin. Another, smaller D. fluviorum followed the pair from around $3 \mathrm{~m}$ distance. The male was captured during mating and had noticeably reddish claspers, which appear to be characteristic of recent mating. A second observation was made at HI on 19 September 2002, at night in similar water depth. No third individual was present on that occasion. Upon capture, the male was also observed to have reddish claspers. Another female was caught from HI on 31 October 2002 with fresh mating bite marks on both pectoral fins. Three $A$. narinari were caught at WWB in January 2005, including two mature animals captured on 24 January engaged in courtship behavior similar to that described by Tricas (1980). That pair was observed for approximately $15 \mathrm{~min}$ while swimming together in shallow water $(0.5$ to $1.5 \mathrm{~m}$ depth) in the intertidal, regularly entering fringing mangrove forest.

Overall recapture rates for tagged elasmobranchs varied from $0 \%$ in six species to $20.5 \%$ in $H$. toshi. All recaptures were obtained during research collection activities, and all occurred at the site of initial tagging. Recapture intervals ranged from 0 to 65 days in tagged H. toshi. Fifteen $H$. toshi between 23 and $49 \mathrm{~cm}$ DW were tagged at HI between August and November 2002, and four (26.7\%) of those individuals were recaptured between one and four times during that period, suggesting that at least some rays exhibited a high rate of site fidelity. Recapture rates were also relatively high overall in N. kublii $(16.1 \%)$, with individual times of liberty ranging from 0 to 1,081 days. Twenty-six D. fluviorum were tagged and released during a short-term study at WWB between January and March 2005, of which five were recaptured at the same site after 3 to 40 days at liberty. There were no $D$. fluviorum recaptures from the other locations.

The broad size range of dasyatid rays collected suggests that sampling techniques were not particularly size-selective, at least for specimens larger than $10 \mathrm{~cm}$ DW. However, there was observational evidence of gear selectivity for myliobatid rays and shark species. Aetobatus narinari were frequently seen to encounter the seine net without becoming enmeshed, and observations at WWB suggest that their abundance at that site was higher than the number captured suggests. Similarly, Orectolobus maculatus and Chiloscyllium punctatum were both occasionally observed, but rarely captured, in the intertidal zone at night at $\mathrm{OMB}$ and WWB. Chiloscyllium punctatum did become enmeshed on several occasions while attempting to prey on mullet that were caught in the net. Chiloscyllium punctatum were regularly observed lying among root systems in mangrove forests at high tide during the night at WWB between January and March 2005.

\section{DISCUSSION}

The Moreton Bay intertidal zone contains a rich elasmobranch diversity compared with that in other areas of similar habitat worldwide, particularly with regard to stingray species. The 13 elasmobranch species recorded from the Moreton Bay intertidal in this study represent $24 \%$ of the 54 elasmobranch species previously recorded from the bay (Johnson 1999, Kyne et al. 2005). Our study differed from that of Johnson (1999) in the methodologies used and through focusing sampling solely on intertidal sand flats, resulting in increased catches of benthic batoids. Pillans et al. (2007) used intertidal sampling techniques similar to those of this study, albeit focusing on daytime low tides, in the north and south regions of Moreton Bay. Eight and five elasmobranch species were collected in each respective area (Pillans et al. 2007), including the cowtail stingray, Pastinachus atrus, and the pigeye whaler shark, Carcharbinus amboinensis, which were not observed in this study. Dasyatis fluviorum, H. toshi, and N. kublii were found at all four of the study sites sampled by Pillans et al. (2007), suggesting that they may be broadly present through the intertidal margins of the bay. 
The Australian elasmobranch fauna is highly biodiverse compared with that of other regions of the world, and a suite of species is found in productive nearshore habitats (Last and Stevens 2009). Thirteen families and 28 species were recorded from shallow $(<3 \mathrm{~m})$ habitats in Shark Bay, Western Australia (White and Potter 2004, Vaudo and Heithaus 2009), compared with nine families and 15 species recorded from Moreton Bay by Pillans et al. (2007) and in our study. Three elasmobranch species were recorded from similarly mangrove-fringed intertidal areas in the Dampier Archipelago, northwestern Australia, using a combination of techniques including seine and gill nets and snorkel surveys (Blaber et al. 1985). Four elasmobranch species were recorded from seine netting in Albatross Bay in the Gulf of Carpentaria (Blaber et al. 1995), and three species were taken from the nearby Embley estuary using seine nets and eight species were caught using stake nets (Blaber et al. 1989).

Although most of the abundant or common species in the Moreton Bay intertidal zone were present over a range of sizes and maturity classes, some sexual or ontogenetic segregation was noted within these habitats. Populations of the most abundant species, $N$. kublii and D. fluviorum, both showed a significant female bias. Pierce et al. (2009) noted that $N$. kublii was sexually segregated between sites in the bay, and the results of this study suggest that D. fluviorum may also be segregated by sex or size. The lack of small D. $f l u$ viorum caught, other than at $\mathrm{HI}$, is an interesting result in itself. The methods used in this study were shown to be capable of catching rays of close to the recorded size-at-birth of D. fluviorum $(11 \mathrm{~cm}$ [Last and Stevens 2009]), suggesting that small juveniles were not generally present in the surveyed habitats during the time of sampling. Dasyatis fluviorum is a euryhaline species (Last and Stevens 2009). Neonates and juveniles of some euryhaline elasmobranchs will preferentially use brackish or freshwater riverine habitats (Simpfendorfer et al. 2005, Thorburn et al. 2007), which may serve to minimize mortality of these young age classes (Heupel et al.
2007). It is possible that $D$. fluviorum juveniles utilize similar habitats. Small D. fuviorum of close to birth size have previously been reported from the Nerang and Macleay rivers in southeastern Queensland and northern New South Wales, respectively (Moreton 1989, Macbeth et al. 2002).

Pronounced east-west gradients in water quality and turbidity within Moreton Bay have been shown to influence teleost fish community composition (Blaber and Blaber 1980, Tibbetts and Connolly 1998). Our study found a high diversity of benthic elasmobranch species at the two NSI sites, which are characterized by relatively clear water and near-oceanic salinities (Dennison and Abal 1999). Seven species were recorded solely from those two eastern sites, although $A$. narinari, C. punctatum, and O. maculatus also utilize subtidal areas in the western bay (S.J.P., pers. obs.). The two western sites were dominated by $N$. kublii. However, the sampling techniques used in this study were not standardized for effort or temporal variation, so these data are observational in nature. Habitats at the two western sites have been degraded by anthropogenic impacts. Major sources of turbidity in the western bay, such as the Brisbane River, were historically much cleaner before human influences began affecting catchments (Davie et al. 1990, Dennison and Abal 1999, Johnson 1999). It is therefore difficult to disentangle the potential effects of direct human processes from natural physicochemical influences.

A number of elasmobranch species that had previously been reported from shallowwater habitats in Moreton Bay (Johnson 1999) were not observed in this study. There is a single historical record of the mangrove whipray, $H$. granulata, but its occurrence has not since been confirmed, and this record may represent a misidentification. Other species at the edge of their range such as the southern eagle ray, Myliobatis australis, may be naturally rare within the bay. However, several of the species that were rarely recorded in our study are more common in deeper areas of the bay or in different habitats (Johnson 1999), suggesting that elasmobranch populations within 
Moreton Bay may be partitioned by region, depth, habitat, or time. Smaller specimens of $H$. tosh $i$ were regularly caught during daylight hours, suggesting a diel pattern of habitat utilization different than that of sympatric dasyatid stingrays, which were caught more frequently at night. A distinct seasonal cycle of species presence and abundance was noted in Shark Bay (Vaudo and Heithaus 2009), and observational data from our study suggest that use of standardized techniques would likely show a similar pattern of occurrence within Moreton Bay.

Although the use of inshore habitats as nursery habitats has not been quantitively demonstrated in rays to date (Pierce et al. 2009), several of the species recorded in the study reported here have commonly been reported from intertidal habitats throughout the northern half of Australia. Newborn and small juvenile G. typus were common within the Moreton Bay intertidal in this study and were also the most abundant species in Shark Bay in Western Australia, where small juveniles similarly dominated catches (Vaudo and Heithaus 2009). Neonate G. typus can also be commonly observed in shallow reef lagoons within the Great Barrier Reef (M.B.B., pers. obs.). The intertidal population of $H$. tosh $i$ was also predominantly composed of immature animals, as were D. fluviorum and N. kublii at some of the study sites (Pierce et al. 2009). Utilization of intertidal habitats may offer several advantages to juvenile elasmobranchs, including predator avoidance (Vaudo and Heithaus 2009), elevated body temperatures (Hight and Lowe 2007) and, potentially, rich feeding opportunities. Most dissected rays from all species had full stomachs (S.J.P., unpubl. data), indicating that this environment is important for feeding or digestion.

Tagging results suggest that relatively small areas of intertidal habitat may be repeatedly used by individual stingrays. Tagging studies indicate that some N. kublii (Pierce et al. 2009) and H. toshi have a high fidelity to small geographical areas over shortto medium-term time scales (i.e., weeks to months). Although previous studies on the movement patterns of benthic sharks (Heupel and Bennett 2007) and rays (Cartamil et al. 2003, Vaudo and Lowe 2006, Le Port et al. 2008) suggest that these species may have naturally small activity spaces, reports of two tagged D. sabina traveling 80 and $97 \mathrm{~km}$, respectively, along the eastern coast of the United States (Schwartz and Dahlberg 1978) suggest that even small stingray species are capable of relatively long-distance dispersion. All recaptures of tagged animals in our project were made by research workers. Although this may simply indicate that there is a low fishing pressure on this group within central Moreton Bay, a high rate of tag shedding was demonstrated within N. kublii (Pierce et al. 2009). If other dasyatids showed a similar rate of tag loss then the reported recapture rate is likely to be an underestimate. Internal tags, such as passive integrated transponder tags (Kohler and Turner 2001), could in future be considered in cases where most recaptures are expected to be collected by project researchers. Tagging studies on intertidal batoids can usefully complement broader life history studies on some of these poorly known species. In this study, the recapture of tagged N. kublii allowed both the measurement of wild growth rates and the validation of annual vertebral band-pair formation in calcein-injected specimens (Pierce and Bennett 2009).

Courtship behavior was observed in both $D$. fluviorum and A. narinari, providing an indication of the timing of mating for these species in southeastern Queensland. Uterine eggs were observed in D. fluviorum and T. testacea during summer and early autumn. Sympatric N. kublii give birth in February/March (Pierce et al. 2009), and parturition of $A$. rostrata in Moreton Bay occurs in November/ December (Kyne and Bennett 2002), indicating that the reproductive cycles of these four ray species are not synchronous within the region. Neonate G. typus were caught between March and May, indicating a possible time of parturition in this species. This study also provides the first available data on size at maturity for both female and male D. fluviorum and for male H. toshi. Female D. fluviorum appear to mature at a substantially larger size than males, at $63.9 \mathrm{~cm}$ compared with 41.2 
cm DW. Although female dasyatids often mature at larger sizes than males (Smith et al. 2007, Pierce et al. 2009), the observed differential in this species is larger than that noted in previously studied stingray species.

Stingrays were the most common large predators found within the intertidal environment in this study. Stingrays play an important role in structuring soft substrate environments both indirectly, via sediment turnover, and directly through predation on invertebrates (Reidenauer and Thistle 1981, VanBlaricom 1982, Thrush et al. 1991, Cross and Curran 2000). Unpublished data on the diet of stingrays within the bay, gathered during fieldwork for this study, show that N. kublii and $D$. fluviorum in particular have major dietary overlaps with other sympatric vertebrate species such as migratory shorebirds (Zharikov and Skilleter 2002, 2003, 2004). An absence of baseline information on batoid abundance makes it difficult to assess how apparent declines in some species, such as D. fluviorum (Kyne et al. 2003), may have affected nearshore ecosystems. The ecological role of these inshore mesopredators is poorly known, and this remains an important area for future research.

Batoids were found to be abundant within the soft-shore intertidal ecosystem of Moreton Bay, with high species diversity present over a small spatial scale (albeit a 4-yr temporal scale). The local abundance of $D$. fluviorum, a threatened Australian endemic (Pierce and Bennett 2010), is a noteworthy result of this study. Moreton Bay, as one of the only substantial areas of suitable habitat in southeastern Queensland, is likely to be an important center of population for the species. Moreton Bay Marine Park, which totally encompasses the bay, was rezoned in 2008 to increase fully protected areas from $0.5 \%$ to $16 \%$ of the park. This protection includes some of the intertidal habitats on the western coast of NSI, which support a high diversity of elasmobranchs. Based on the results of the work reported here, such protection could potentially confer localized benefits for $D$. $f u$ viorum and other sympatric species. This work provides a useful baseline on the elasmobranch species that utilize these habitats in southeastern Queensland waters and indicates that, despite localized degradation, Moreton Bay remains an important elasmobranch habitat in eastern Australia.

\section{ACKNOWLEDGMENTS}

We thank all the University of Queensland students and volunteers who assisted in the field during the duration of this project, particularly Sebastian Pardo, Jon Combs, and Scott Cutmore. Stephen Taylor assisted with both editorial comments and help in fieldwork. Thanks also to John Page for his help in providing additional specimens. Chris Glen provided assistance with figures. Much of the fieldwork for this project was conducted with the assistance of the Moreton Bay Research Station on North Stradbroke Island, and use of their facilities is very gratefully acknowledged. This research was conducted under General Fisheries Permit PRM03951I, 55543 and Animal Ethics Approvals from The University of Queensland. Thanks to Charlie Huveneers and Colin Simpfendorfer for their comments on an early version of the manuscript, and also to two anonymous reviewers for their helpful suggestions.

\section{Literature Cited}

Blaber, S. J. M., and T. G. Blaber. 1980. Factors affecting the distribution of juvenile estuarine and inshore fish. J. Fish Biol. 17:143-162.

Blaber, S. J. M., D. T. Brewer, and J. P. Salini. 1989. Species composition and biomasses of fishes in different habitats of a tropical northern Australian estuary: Their occurrence in the adjoining sea and estuarine dependence. Estuarine Coastal Shelf Sci. 29:509-531.

2. 1995. Fish communities and the nursery role of the shallow inshore waters of a tropical bay in the Gulf of Carpentaria, Australia. Estuarine Coastal Shelf Sci. 40:177-193.

Blaber, S. J. M., J. W. Young, and M. C. Dunning. 1985. Community structure and zoogeographic affinities of the coastal fishes of the Dampier Region of north-western 
Australia. Aust. J. Mar. Freshwater Res. 36:247-266.

Cartamil, D. P., J. J. Vaudo, C. G. Lowe, B. M. Wetherbee, and K. N. Holland. 2003. Diel movement patterns of the Hawaiian stingray, Dasyatis lata: Implications for ecological interactions between sympatric elasmobranch species. Mar. Biol. (Berl.) 142:841-847.

Chilvers, B. L., I. R. Lawler, F. Macknight, H. Marsh, M. Noad, and R. Paterson. 2005. Moreton Bay, Queensland, Australia: An example of the co-existence of significant marine mammal populations and large-scale coastal development. Biol. Conserv. 122:559-571.

Clarke, K., and R. Gorley. 2001. PRIMER v5: User manual/tutorial. PRIMER-E, Plymouth, United Kingdom.

Clarke, K., and R. M. Warwick. 2001. Change in marine communities: An approach to statistical analysis and interpretation. 2nd ed. PRIMER-E, Plymouth, United Kingdom.

Cross, R. E., and M. C. Curran. 2000. Effects of feeding pit formation by rays on an intertidal meiobenthic community. Estuarine Coastal Shelf Sci. 51:293-298.

Davie, P., E. Stock, and D. Low Choy, eds. 1990. The Brisbane River: A source-book for the future. Australian Littoral Society, Inc., in association with the Queensland Museum, Brisbane.

Dennison, W. C., and E. G. Abal. 1999. Moreton Bay study: A scientific basis for the healthy waterways campaign. South East Queensland Regional Water Quality Management Strategy, Brisbane.

EPA. 2008a. Final public benefit test report for the Marine Parks (Moreton Bay) Zoning Plan 2008. Queensland Government Environmental Protection Agency, Brisbane.

—. 2008b. Moreton Bay Marine Park user guide. Queensland Government Environmental Protection Agency, Brisbane.

Fowler, S. L., R. D. Cavanagh, M. Camhi, G. H. Burgess, G. M. Cailliet, S. V. Fordham, C. A. Simpfendorfer, and J. A. Musick, eds. 2005. Sharks, rays and chimaeras: The status of the chondrichthyan fishes.
IUCN/SSC Shark Specialist Group. IUCN, Gland.

Francis, M. P. 2006. Morphometric minefields: Towards a measurement standard for chondrichthyan fishes. Environ. Biol. Fishes 77:407-421.

Friedlander, A. M., and E. E. DeMartini. 2002. Contrasts in density, size, and biomass of reef fishes between the Northwestern and the main Hawaiian Islands: The effects of fishing down apex predators. Mar. Ecol. Prog. Ser. 230:253-264.

Heithaus, M. R. 2004. Predator-prey interactions. Pages 487-521 in J. C. Carrier, J. Musick, and M. R. Heithaus, eds. Biology of sharks and their relatives. CRC Press, Boca Raton, Florida.

Heupel, M. R., and M. B. Bennett. 2007. Estimating abundance of reef-dwelling sharks: A case study of the epaulette shark, Hemiscyllium ocellatum (Elasmobranchii: Hemiscyllidae). Pac. Sci. 61:383-394.

Heupel, M. R., J. K. Carlson, and C. A. Simpfendorfer. 2007. Shark nursery areas: Concepts, definition, characterization and assumptions. Mar. Ecol. Prog. Ser. 337:287-297.

Hight, B. V., and C. G. Lowe. 2007. Elevated body temperatures of adult female leopard sharks, Triakis semifasciata, while aggregating in shallow nearshore embayments: Evidence for behavioral thermoregulation? J. Exp. Mar. Biol. Ecol. 352:114-128.

Jackson, J. B. C., M. X. Kirby, W. H. Berger, K. A. Bjorndal, L. W. Botsford, B. J. Bourque, R. H. Bradbury, R. Cooke, J. Erlandson, J. A. Estes, T. P. Hughes, S. Kidwell, C. B. Lange, H. S. Lenihan, J. M. Pandolfi, C. H. Peterson, R. S. Steneck, M. J. Tegner, and R. R. Warner. 2001. Historical overfishing and the recent collapse of coastal ecosystems. Science (Washington, D.C.) 293:629-638.

Johnson, J. W. 1999. Annotated checklist of the fishes of Moreton Bay, Queensland, Australia. Mem. Queensl. Mus. 43:709-762.

Kohler, N. E., and P. A. Turner. 2001. Shark tagging: A review of conventional methods and studies. Environ. Biol. Fishes 60:191-223. 
Kyne, P. M., and M. B. Bennett. 2002. Reproductive biology of the eastern shovelnose ray, Aptychotrema rostrata (Shaw and Nodder, 1794), from Moreton Bay, Queensland, Australia. Mar. Freshwater Res. 53:583589.

Kyne, P. M., J. W. Johnson, A. J. Courtney, and M. B. Bennett. 2005. New biogeographical information on Queensland chondrichthyans. Mem. Queensl. Mus. 50:321-327.

Kyne, P. M., D. A. Pollard, and M. B. Bennett. 2003. Dasyatis fuviorum. 2007 IUCN Red list of threatened species (http://www .iucnredlist.org/details/41797/0).

Last, P. R., B. M. Manjaji-Matsumoto, and J. J. Pogonoski. 2008. Himantura astra sp. nov., a new whipray (Myliobatoidei: Dasyatidae) from northern Australia. Pages 303-314 in P. R. Last, T. White, and J. J. Pogonoski, eds. Descriptions of new Australian chondrichthyans. Australia CSIRO Marine and Atmospheric Research Paper no. 022.

Last, W., and J. D. Stevens. 2009. Sharks and rays of Australia. 2nd ed. Australia CSIRO Publishing, Melbourne.

Le Port, A., T. Sippel, and J. C. Montgomery. 2008. Observations of mesoscale movements in the short-tailed stingray, Dasyatis brevicaudata, from New Zealand using a novel PSAT tag attachment method. J. Exp. Mar. Biol. Ecol. 359:110-117.

Lotze, H. K., H. S. Lenihan, B. J. Bourque, R. H. Bradbury, R. G. Cooke, M. C. Kay, S. M. Kidwell, M. X. Kirby, C. H. Peterson, and J. B. C. Jackson. 2006. Depletion, degradation, and recovery potential of estuaries and coastal seas. Science (Washington, D.C.) 312:1806-1809.

Macbeth, W. G., D. A. Pollard, A. S. Steffe, S. Morris, and M. Miller. 2002. Relative abundance of fish and crustaceans and water quality following the fish kill of March 2001 in the Macleay River, northern New South Wales. NSW Fisheries Final Report Series No. 39. NSW Fisheries, Cronulla.

Manson, F. J., N. R. Loneragan, and S. R. Phinn. 2003. Spatial and temporal variation in distribution of mangroves in More- ton Bay, subtropical Australia: A comparison of pattern metrics and change detection analyses based on aerial photographs. Estuarine Coastal Shelf Sci. 57:653-666.

Moreton, R. M. 1989. Hydrology and fish fauna of canal developments in an intensively modified Australian estuary. Estuarine Coastal Shelf Sci. 28:43-58.

Pandolfi, J. M., R. H. Bradbury, E. Sala, T. P. Hughes, K. A. Bjorndal, R. G. Cooke, D. McArdle, L. McClenachan, M. J. H. Newman, G. Paredes, R. R. Warner, and J. B. C. Jackson. 2003. Global trajectories of the long-term decline of coral reef ecosystems. Science (Washington, D.C.) 301:955-958.

Pierce, S. J., and M. B. Bennett. 2009. Validated annual band-pair periodicity and growth parameters of blue-spotted maskray, Neotrygon kublii, from south-east Queensland, Australia. J. Fish Biol. 75:2490-2508.

- 2010. Distribution of the estuary stingray (Dasyatis fluviorum) in Australia. Mem. Queensl. Mus. Nature 55:9-17.

Pierce, S. J., S. A. Pardo, and M. B. Bennett. 2009. Reproduction of the blue-spotted maskray Neotrygon kublii (Myliobatoidei: Dasyatidae) in south-east Queensland, Australia. J. Fish Biol. 74:1291-1308.

Pillans, S., J. Ortiz, R. Pillans, and H. Possingham. 2007. The impact of marine reserves on nekton diversity and community composition in subtropical eastern Australia. Biol. Conserv. 136:455-469.

Reidenauer, J. A., and D. Thistle. 1981. Response of a soft-bottom harpacticoid community to stingray (Dasyatis sabina) disturbance. Mar. Biol. (Berl.) 65:261-267.

Robbins, W. D., M. Hisano, S. R. Connolly, and J. H. Choat. 2006. Ongoing collapse of coral-reef shark populations. Curr. Biol. 16:2314-2319.

Schwartz, F. J., and M. D. Dahlberg. 1978. Biology and ecology of the Atlantic stingray, Dasyatis sabina (Pisces: Dasyatidae), in North Carolina and Georgia. Northeast Gulf Sci. 2:1-23.

Simpfendorfer, C. A., G. G. Freitas, T. R. Wiley, and M. R. Heupel. 2005. Distribution and habitat partitioning of immature 
bull sharks (Carcharbinus leucas) in a Southwest Florida estuary. Estuaries 28:78-85.

Smith, W., G. Cailliet, and E. Melendez. 2007. Maturity and growth characteristics of a commercially exploited stingray, Dasyatis dipterura. Mar. Freshwater Res. 58:54-66.

Stevens, J. D., R. Bonfil, N. K. Dulvy, and P. A. Walker. 2000. The effects of fishing on sharks, rays, and chimaeras (chondrichthyans), and the implications for marine ecosystems. ICES J. Mar. Sci. 57:476-494.

Stevenson, C., L. S. Katz, F. Micheli, B. Block, K. W. Heiman, C. Perle, K. Weng, R. Dunbar, and J. Witting. 2007. High apex predator biomass on remote Pacific islands. Coral Reefs 26:47-51.

Stobutzki, I. C., M. J. Miller, D. S. Heales, and D. T. Brewer. 2002. Sustainability of elasmobranchs caught as bycatch in a tropical prawn (shrimp) trawl fishery. Fish. Bull. 100:800-821.

Thompson, J. J. 1993. Patterns of shorebird abundance in eastern Moreton Bay, Queensland. Wildl. Res. 20:193-201.

Thorburn, D. C., D. L. Morgan, A. J. Rowland, and H. S. Gill. 2007. Freshwater sawfish Pristis microdon Latham, 1794 (Chondrichthyes: Pristidae) in the Kimberley region of Western Australia. Zootaxa 1471:27-41.

Thrush, S. F., R. D. Pridmore, J. E. Hewitt, and V. J. Cummings. 1991. Impact of ray feeding disturbances on sandflat macrobenthos: Do communities dominated by polychaetes or shellfish respond differently. Mar. Ecol. Prog. Ser. 69:245-252.

Tibbetts, I. R., and R. M. Connolly. 1998. The nekton of Moreton Bay. Pages 395-420 in I. R. Tibbetts, N. J. Hall, and W. C. Dennison, eds. Moreton Bay and catchment. School of Marine Science, The University of Queensland, Brisbane.
Tricas, T. C. 1980. Courtship and matingrelated behaviors in myliobatid rays. Copeia 1980 (3): 553-556.

VanBlaricom, G. R. 1982. Experimental analyses of structural regulation in a marine sand community exposed to oceanic swell. Ecol. Monogr. 52:283-305.

Vaudo, J. J., and M. R. Heithaus. 2009. Spatiotemporal variability in a sandflat elasmobranch fauna in Shark Bay, Australia. Mar. Biol. (Berl.) 156:2579-2590.

Vaudo, J. J., and C. G. Lowe. 2006. Movement patterns of the round stingray Urobatis balleri (Cooper) near a thermal outfall. J. Fish Biol. 68:1756-1766.

Walker, T. I. 2005. Reproduction in fisheries science. Pages 81-127 in W. C. Hamlett, ed. Reproductive biology and phylogeny of Chondrichthyes. Science Publishers, USA.

White, W. T., and I. C. Potter. 2004. Habitat partitioning among four elasmobranch species in nearshore, shallow waters of a subtropical embayment in Western Australia. Mar. Biol. (Berl.) 145:1023-1032.

Zharikov, Y., and G. A. Skilleter. 2002. Sexspecific intertidal habitat use in subtropically wintering bar-tailed godwits. Can. J. Zool. 80:1918-1929.

- 2003. Depletion of benthic invertebrates by bar-tailed godwits Limosa lapponica in a subtropical estuary. Mar. Ecol. Prog. Ser. 254:151-162.

. 2004. Potential interactions between humans and non-breeding shorebirds on a subtropical intertidal flat. Aust. Ecol. 29:647-660.

Zharikov, Y., G. A. Skilleter, N. R. Loneragan, T. Taranto, and B. E. Cameron. 2005. Mapping and characterising subtropical estuarine landscapes using aerial photography and GIS for potential application in wildlife conservation and management. Biol. Conserv. 125:87-100. 
